\title{
REX ASIAE ET PONTI POKLONITVENO DELO CYPRIANA DE ROREJA
}

\author{
Bernhard M e i e r (Pfäffingen)
}

Cyprian de Rore je eden tistih glasbenikov, katerih življenje se je odvijalo večinoma $\mathrm{v}$ službi knežjih dvorov. Je pa tudi eden tistih mojstrov, katerim je tu uspelo doseči slavo in čast ter razen tega še dobro dotirano službeno mesto. ${ }^{1} \mathrm{~V}$ skladu s to značilnostjo Rorejevega življenja in delovanja najdemo $\mathrm{v}$ njegovi ustvarjalnosti veliko število del, ki so nastala kot poklonitev visokim osebnostim ali pa so spremljala in slavila dogodke iz dvornega in političnega življenja tistega časa. ${ }^{2}$ Mnoga teh del so, kar zadeva njihove zveze in nekdaj aktualni povod za nastanek, vse do zadnjega časa razlagali napak. Ne nazadnje velja to tudi za mojstrov latinski madrigal Rex Asiae et Ponti, ki je prvič izšel $\mathrm{v}$ tisku kmalu po Rorejevi smrti. ${ }^{3} \mathrm{~V}$ nadaljevanju nameravam obravnavati vsebino besedila in vprašanje naslovljenca ter domnevnega datiranja tega dela. Poprej pa je treba rešiti nekatere filološke težave, ki zdaj še ovirajo interpretacijo. Zavoljo orientacije naj najprej podam tekst $\mathrm{v}$ obliki, kot ga je posredoval Alfred Einstein. ${ }^{4}$ Tu se ta glasi takole:

1 Prim. C. Anthon, Some Aspects of the Social Status of Italian Musicians during the Sixteenth Century, Journal of Renaissance and Baroque Music, zv. I, 1946/47, 234.

${ }^{2}$ Glede samega Roreja glej avtorjevo razpravo: Staatskompositionen von $\mathrm{Cy}-$ prian de Rore, Tijdschrift van de Vereniging voor Nederlandse Muziekgeschiedenis, Zv. 21/22, 1969. V večjem obsegu so takšne skladbe obravnavane v odličnem delu A. Dunninga, Die Staatsmotette 1480-1555, Utrecht 1969.

3 Prvi natis: Le Vive Fiamme de' vaghi e dilettevoli Madrigali dell' eccellentissimo Musico, Cipriano Rore..., Venezia 1565 (=RISM 156518). Izdaja: Cipriani Rore Opera Omnia, izdal B. Meier (CMM 14, Roma 1959), zv. V (v tisku). - Naziv »latinski madrigal« je zasilna oznaka kompozicijske vrste, ki menda tisti čas sploh ni imela lastnega imena, po svojem značaju pa je omahovala med tremi natančno določenimi zvrstmi, kot so motet, madrigal in humanistična oda. Ta vrsta kompozicije je povezana $\mathrm{z}$ motetom po latinskem tekstu, $\mathrm{z}$ madrigalom pa - vsaj pri Roreju - glede načina njenega posredovanja. Po drugi strani jo loči tako od moteta kot od madrigala kompozicijska faktura, ki se večinoma odvija $\mathrm{v}$ stavku nota proti noti. Po takšni strukturi je delo, kot je Rex Asiae et Ponti, blizu humanistični odi. Vendar jo od te spet loči to, da ni merodajen za uglasbitev metrum teksta, ampak njegova akcentuacijska deklamacija in da skladatelj mestoma uporablja, zlasti v smislu zaključnega stopnjevanja, imitacijo.

${ }^{4}$ A. Einstein, The Italian Madrigal, Princeton 1949, zv. I, 388. 
$\gg$ Rex Asiae et Ponti potuit celeberrimus olim

Linguarum varios ore sonare modos:

Divitiis alios longe superaverat omnes Imperii cuius maxima Roma tui:

Rebus Alexander gestis clarissimus orbis Inclitus immensi Rex dominator fuit:

$\mathrm{O}$ prisce Wolffange decusque et gloria stirpis Augspurge [sic] qua se carmina iactat ovans:

His quaque fortuna parente voluit esse Alma tamen virtus annumerare cupit.«

Osnova te verzije je verzija dveh poznejših virov obravnavanega dela. ${ }^{5}$ Vsekakor je treba pripomniti, da posredujeta $\mathrm{v}$ četrtem distihu tako ta kot primarni vir RISM $1565^{18}$ le obliko »Auspurge« in ne oblike »Augspurge«, ki jo je rekonstruiral, ne da bi to omenil, Einstein. Enako ne beremo v tretjem distihu »dominator «, ampak - tako kot v vseh virih — »domitorque«. Razen tega je treba pripomniti, da je besedilo ne glede na Einsteinovi napaki deloma nerazumljivo in popačeno. Drugi in peti distihon nimata nikakršnega smisla. $\mathrm{V}$ petem distihu pa kažejo variante tudi na to, da že stavci niso več razumeli primarnega vira besedila in da so ga lahko stavili le po napačni predlogi. ${ }^{6}$ Po korekturi vseh slovničnih napak in s smiselno dopolnitvijo ločil se potem glasi pesem takole:

»Rex Asiae et Ponti potuit celeberrimus olim Linguarum varios ore sonare modos.

Divitiis alius longe superaverat omnes Imperii civîs [ = cives], maxima Roma, tui.

Rebus Alexander gestis clarissimus orbis Inclitus immensi rex domitorque fuit.

O prisc[a]e Wolffange decusque et gloria stirpis Auspurg[a]e, qua se carmina iactat ovans:

His quamquam fortuna parem te noluit esse, Alma tamen virtus annumerare cupit. «7

5 Di Cipriano de Rore il Quinto Libro di Madrigali a cinque Voci..., Venezia 1566 (=RISM 156617); Il Primo Libro delle Fiamme...., Venezia 1569 (Vogel, Rore, št. 33). Kot četrti vir se je nedavno pojavil rokopis Bibl. Nationale, Paris, Res. Vma. ms. 851 (Bourdeney).

6 Variante v RISM 156518: »quāáue« (Cantus, Altus, Bassus); »parentem《 (Cantus, Quintus); »parentes« (Bassus). Bourdeney sledi s »quāque fortuna parentem« (Cantus, tu edino tekstirani glas) prav tako vzoru RISM $1565^{18}$.

7. Za njihovo pomoč pri popravku se zahvaljuje avtor asistentom seminarja za klasično filologijo univerze $\mathrm{v}$ Tübingenu. — »Noluit« $\mathrm{v}$ zadnjem distihonu potrjuje razen tega še glasba: Rorejeva, tonskemu načinu tuja kadenca - »clausula peregrina « $\mathrm{g}$ v okviru dela, ki je tradicionalnem 5. modusu, dobi svoj smisel le iz izjave 
Prevod: Veleslavni kralj Azije in Ponta je znal izgovarjati glasove različnih jezikov. Po bogastvu je nekdo drug vse državljane tvojega kraljestva, o Rim, prekosil. Po svojih dejanjih veleslavni Aleksander je bil kralj in zavojevalec razsežnega področja. O Wolfgang, okras in slava starega dostojanstvenega »auspurškega « rodu, s katerim se v hvalospevih ponaša. Čeprav ni Fortuna hotela, da si tem enak, pa zahteva tvoja vzvišena »virtus«, da se k njim prištevaš. Nekega Wolfganga, pripadnika »starodavnega dostojanstvenega rodu « — razlaga imenskega adjektiva, ki ga posreduje oblika »Auspurg[a]e«, naj ostane zdaj še neopredeljena - torej primerja doslej neznani pesnik s tremi velikimi možmi antike: $\mathrm{z}$ Aleksandrom Velikim in dvema drugima, neimenovanima. Od teh prepoznamo prvega kot Mitridata Eupatorja, kot »Mitridate, Re di Ponte«, naslovnega junaka znane Mozartove mladostne opere. Na vrhu svoje moči je vladal Mithridates ne le deželi svojega rodu, ampak celotni Mali Aziji. In kot poroča izročilo, je znal vsem dvaindvajsetim narodom, ki jih je obsegalo njegovo kraljestvo, izrekati pravico $\mathrm{v}$ njihovem jeziku. ${ }^{8}$ Rimljan, ki je omenjen $\mathrm{v}$ drugem distihu, pa je lahko le Marcus Licinius Crassus, tisti »najbogatejši med bogatimi«, čigar premoženje je na koncu življenja znašalo 170 milijonov sestercijev. ${ }^{9}$

Zakaj pa imenuje pesnik prav te tri osebe, osebe, ki so si v zvezi le tako, da je njihovo delovanje povezano z Orientom? (Tudi Crassus je bil nazadnje namestnik Sirije in je padel vzhodno od meje svoje province $\mathrm{v}$ boju proti Partom.) In kdo je predvsem tisti, ki mu pesnik in skladatelj posvečata to nenavadno primerjavo kot poklonitev?

Nekoliko previdno se je o tem vprašanju izjavil Einstein. $\mathrm{Na}$ podlagi oblike »Auspurge«, ki jo je potem sam spremenil v »Augspurge«, očitno sodi, da kaže delo na to, kako se je Rore na svojih potovanjih na Nizozemsko ali od tod v Italijo (torej leta 1558/59) tudi mimogrede ustavil v Augsburgu in se povezal $\mathrm{z}$ družino Fugger. ${ }^{10} \mathrm{Zdi}$ se, da zveza $\mathrm{z}$ augsburškimi meščani dejansko obstajajo. Iz augsburške trgovske družine izhaja tudi Hieronymus Uttinger, ki mu posveča Gardano kot svojemu prijatelju in prijatelju

»parem te noluit esse«. Interpretacija besedi »biti drugačen« s pomočjo takšnih tonaliteti tujih klavzul je za 15. stoletje tipičen postopek. Da pa bi bila oblikovana taka klavzula nevedoma, je pri mojstru, kot je Rore, izključeno. (Za interpretacijo besedi in o vprašanju tonalitet $v$ 16. stoletju glej avtorjev prispevek v: Kirchenmusikalisches Jahrbuch, letnik 47, 1963, 75 in dalje; glede pravkar omenjenega uvajanja klavzul, ki so tuje tonaliteti, glej še posebej str. 92 in dalje.)

8 O Mitridatu glej Th. Mommsen, Römische Geschichte, Berlin 1931, zv. II, 266 in dalje.

9 Mommsen TH., ib., zv. III, 14 in 523.

10 Einstein A., ib., zv. I, 387. Za manjšega avtorja kot je L. D. Nuernberger (The Five Voice Madrigals of Cipriano de Rore, disertacija, Ann Arbor 1964, 57) velja Einsteinova domneva že kot nekaj gotovega; sicer pa to ni edini primer, ko sta zavedla tega avtorja slepa vera $\mathrm{v}$ avtoriteto in pomanjkljiv čut pri razlagi tekstov, ki jih je komponiral Rore. 
mojstra svojo prvo knjigo petglasnih motetov (1544). ${ }^{11}$ Vendar pa Wolfganga Fuggerja $\mathrm{v}$ 16. stoletju nikoli ni bilo. ${ }^{12}$

Tako ne ostane drugega, kot da iščemo tega Wolfganga pri drugih patricijskih družinah $\mathrm{v}$ Augsburgu, in to predvsem pri takih, katerih patricijski položaj za razloček od Fuggerjev še ni bil novejšega datuma. Noben od maloštevilnih takrat živečih nosilcev imena Wolfgang, kar jih poznamo po življenjskih podatkih iz augsburških rodbin, pa ni primeren za pojasnitev besedila Rex Asiae et Ponti.

Toda že pred Einsteinom je Walter Weyler pokazal drugo zvezo omenjenega besedila. ${ }^{13}$ Weyler je $\mathrm{v}$ Archivio di Stato $\mathrm{v}$ Modeni odkril pismo verjetno koncept pisma, ki ga je odposlal Rore - z napisom »Cyprianus Rorus Wolffgano Aursperguo《 (pravzaprav »Aurspergio«) in datirano s 1. majem 1556 v Ferrari.

$\mathrm{S}$ tem pismom je našel Weyler tisti dokument, ki bo rešil, kot se bo še pokazalo, vprašanje o naslovljencu Rex Asiae et Ponti. Vendar Weyler ni znal svoje najdbe primerno izkoristiti. Ne da bi se brigal za problem dveh oblik »Aurspergio ( $k a r$ je on bral »Aursperguo $)$ in »Auspurg[a]e«, je kratko malo napravil za naslovljenca pesmi Rex Asiae et Ponti nekega Nemca z imenom »Wolfgang Ausperguo« (sic). In Weyler domneva v tem človeku celo duhovnika. Kako nenavadna je primerjava predstavnika cerkve z Aleksandrom, zavojevalcem sveta, s Crassusom in kraljem Mitridatom, pa menda ta avtor ni opazil. ${ }^{14}$

$\mathrm{Z}$ nekoliko spremenjeno obliko imena (»Wolfgang Auspergus«) je Weylerjevo tolmačenje pesmi Rex Asiae et Ponti tudi prešlo v sicer zelo dobro študijo Alvina R. Johnsona o Rorejevih duhovnih delih. ${ }^{15}$ Zakaj pa se nahaja - če predpostavljamo (sprva še hipotetično), da sta naslovljenec Rorejevega pisma in oseba, ki jo slavi besedilo kompozicije, zares isti človek - v Rorejevem pismu oblika »Aurspergio«? Ta oblika skoraj ne more temeljiti na napaki pisarja vojvodske pisarne $\mathrm{v}$ Ferrari. Zakaj $\mathrm{v}$ tem primeru bi ne bilo italijanizirano tuje ime, ampak bi prišlo do vrste konsonantov, ki so italijanščini kakor tudi latinščini povsem tuji (likvida + dve muti). Pač pa najdemo pogosto takšno vrsto konsonantov $\mathrm{v}$ nemških besedah. Če gledamo $\mathrm{z}$ vidika fonetike nemškega jezika, se zdi, da je oblika »Aurspergio« bližja izvirniku.

11 Augsburški trgovec Georg Uttinger se pojavi 1517, 1530 in 1540 med »consules« v Fondaco dei Tedeschi v Benetkah, torej je bil tam ugledna osebnost. Gl. $\mathrm{H}$. Simonsfeld, Der Fondaco dei Tedeschi in Venedig und die deutsch-venezianischen Handelsbeziehungen, zv. II, Stuttgart 1887, 178.

12 G1. rodovnik rodbine v G. Freiherr von Pölnitz, Die Fugger, Frankfurt a. M. $1960,395$.

13 W. Weyler, De Teksten van de Rore's Madrigalen, Vlaamsch Jaarboek voor Muziekgeschiedenis, zv. IV, 1942, str. 168, zlasti op. 12. Signatura pisma, ki ga tu posreduje Weyler, je: Modena, Archivio di Stato, Cancelleria Ducale, Archivii speciali, Busta 22.

${ }_{14}$ Značilno, da Weyler celo enači Aleksandra $\mathrm{z}$ »Rex Asiae et Ponti«; omenjeni naslov Mozartove opere mu najbrž ni bil znan.

15 A. R. Johnson, The Liturgical Music of Cipriano de Rore, disertacija, New Haven/Conn. 1954, 343. 
Hkrati pa kaže tudi na staro plemiško rodbino v tedanji Notranji Avstriji, na rodbino Auersperg, ime, ki so ga $\mathrm{v}$ tistem času pisali tudi $»$ Aursperg $\ll{ }^{16}$

Cit. Rorejevo pismo se glasi v celoti takole:

»Cyprianus Rorus Wolffgano Aurspergio Carniae Comiti S. D. Cum maxima semper erga te universamque familiam tuam observantia propensus fuerim[,] quacunque mihi oblata occasione[,] quanta te prosequerer veneratione, ipsa etiam mearum virium imbecillitate aperto animo explicavi. Quod cum meum sit propositum mihi in perpetuo vitae cursu servandum: nunc pariter[,] postquam quaedam accepi carmina in laudem tuam non minus vere quam egregie conscripta[,] ea tanti féci[,] ut ab ipsis artem musicam posse splendorem capere existimaverim, ac quoniam in praeclarissimis aliis virtutibus hac una maxime polles, hunc meum laborem tibi non ingratum fore censui: ipsosque propterea versus suis numeris harmoniae accom[m]odatos tibi mitto. Teque etiam atque etiam oro[,] ut me tibi esse addictissimum tuique studiosissimum certo scias. Vale.

Cal. Maij. M. D. L. VI. Ferrariae.«

Prevod:

»Cyprianus Rore pozdravlja grofa Wolfganga Aurspergiusa iz »Carnie«. Ker sem bil Tebi in vsej Tvoji družini vselej naklonjen $\mathrm{z}$ največjim spoštovanjem, sem pri vsaki priložnosti, ki se mi je nudila, odkritosrčno - čeprav pri vsej šibkosti svojih moči - pokazal, kako Te častim. Ker je to moja namera, ki jo bom ohranil skozi vse življenje, sem Te tudi sedaj, potem ko sem prejel nekaj odlično sestavljenih in resničnih verzov ${ }^{17}$ Tebi $\mathrm{v}$ hvalo, tako visoko cenil, da sem bil mnenja, da bodo glasbi $v$ čast. In ker se razen $\mathrm{z}$ drugimi slovitimi sposobnostmi odlikuješ še posebno tudi s to (»ars musica «), sem mislil, da Ti to moje delo ne bo nezaželeno. Zato Ti pošiljam te verze, opremljene $z$ glasbo [, ki jim pripada] in Te vselej znova prosim, da veš, kako sem Ti čisto vdan in Tvoj. Zbogom.«

Kot se zdaj kaže, nam dá že samo napis Rorejevega pisma, ki ga Weyler ni v celoti priobčil, spoznati, da moramo imeti za naslovljenca dejansko pripadnika družine Auerspergov. Kajti »Carnia« je tu latinizirana oblika imena dežele $\mathrm{Kranjske}^{18}$ in v tej vojvodini je družina Auerspergov tudi živela. Nadalje pokaže rodovnik rodbine, da je prav za časa Roreja bil nekdo iz tako imenovane Schönbergove linije, ${ }^{19} \mathrm{ki}$ je nosil ime Wolfgang Engelbert I. ( $\uparrow 1557$, rojstni datum je doslej nepoznan).

16 Zadnji način pisanja ima npr. J. L. Schönleben, Genealogia illustrissimae familiae principum, comitum et baronum ab Aursperg (Labaci 1681). Na istočasno obstajanje oblik »Aursperg « in »Auersberg« opozarja J. W. Valvasor, Die Ehre des Herzogthums Crain, 1689, zv. III/1, 99.

17 Prevod »verzov« podpira tudi dejstvo, da je lahko naslovljenec celo v hvalospevu, ki obsega le tri distihe, naprošen, da te »carmina milostno sprejme. (Leonhard Lechner, motet Te quia Pieridum; gl. L. Lechner, Werke I, izdal L. Finscher, Kassel 1956, 61).

18 Po ljubeznivem sporočilu Avstrijskega državnega arhiva (oddelek Haus-, Hofund Staatsarchiv), Dunaj.

19 Drugi Wolfgang Engelbert von Auersperg, ki je z imenovanim v daljnjem sorodstvu, je bil rojen šele leta 1553 in zato kot naslovljenec Rorejevega dela ne pride $\mathrm{v}$ poštev. 
Ali ustrezajo razen imena Wolfgang tudi druge izjave $\mathrm{v}$ besedilu Rex Asiae et Ponti tej osebi? Nedvomno velja to za hvalo glede porekla iz »starodavno dostojanstvenega rodu «. Kajti družina Auersperg je spadala med najstarejše rodbine dežele. Na Kranjskem je bila, kot omenja pripovedka, že vse od Karla Velikega, dejansko pa vsaj že od 13. stoletja dalje. Tudi to, da so pri njem lahko hvalili le »virtus« - možnost, da posnema junake antike se ujema $\mathrm{z}$ Wolfgangom Engelbertom I., ker v zvezi z njegovim življenjem zgodovina ne vé ničesar poročati o velikih dejanjih. Kot njegov oče si je tudi Wolfgang Engelbert vneto prizadeval, da bi povečal rodbinsko posest. Primerjava z Rimljanom Crassusom se zdi prav glede na te okolnosti verjetna. Ravno tako realno ozadje lahko vidimo v namigovanju na Mitridata, ki je bil vešč jezikov. Kranjska s sosednimi deželami je bila dežela mnogih jezikov. Razen slovenščine, ki je variirala glede na različna narečja, so takrat $\mathrm{v}$ deželi govorili tudi nemško - v kočevskem jezikovnem otoku svojstven dialekt -, hrvaško in laško. Kranjski plemič je moral znati govoriti te jezike. Navajanje Aleksandra - in sploh »orientalni « značaj vzornih oseb, ki jih omenja pesnik - pa pojasnjuje zgodovina družine Auersperg in njene domovine. Kranjska je bila v 16. stoletju tako kot druge avstrijske dežele mejno področje, ki so ga ogrožali Turki. Na tej vzhodni meji rimsko-nemškega cesarstva je bila skoro nepretrgoma ogorčena borba. V bojih s Turki pa so se odlikovali različni člani družine Auersperg, med njimi tudi bližnji sorodniki Wolfganga Engelberta I. Stari stric Wolfganga Engelberta (Wilhelm von Auersperg) je bil prvi, ki je bil, ko je prišla turška nevarnost, leta 1469 imenovan v novoustanovljeni urad »generala hrvaških in obmorskih meja«.

Ko so turške drhali prodrle leta 1532 do Zgornje Avstrije, je Georg von Auersperg, brat Wolfganga Engelberta, te zmagoslavno pobil. Johannes, oče Wolfganga Engelberta pa je bil ubit na poti - najbrž od Turkov -, ko je hitel leta 1529 na pomoč obleganemu Dunaju. ${ }^{20}$

Če izhajamo iz imena »Wolffganus Aurspergius« = Wolfgang Engelbert von Auersperg, ki ga izpričuje Rorejevo pismo, lahko razložimo vse, kar je povedanega v pesmi Rex Asiae et Ponti. Ovira pri tem je le še oblika »Auspurg[a]e«. Spričo toliko drugih napak v tem besedilu pa lahko domnevámo, če že ne povsem gotovo trdimo, da gre tudi tu za nesporazum. Ime mesta Augsburg so poznali v Benetkah bolje kot »Auspergae«, kar je domnevno latinizirana oblika imena Auersperg.

20 Domnevna starost rodbine Auersperg: Schönleben, ib.; od tod je to prevzel tudi J.H. Zedler v Grosses vollständiges Universal-Lexikon, zv. II, Halle, Leipzig 1732, stolpec 2144. Wolfgang Engelbert I, razširjevalec rodbinskih posesti: P. von Radics, Herbard VIII., Freiherr von Auersperg (Wien 1862), 53. (Za posredovanje teh in drugih odlomkov iz navedenega dela se avtor zahvaljuje že v op. 18 omenjenemu oddelku Avstrijskega državnega arhiva na Dunaju). Mnogojezičnost Kranjske: Valvasor, ib., zv. I, 210 in dalje, in 255. Wilhelm von Auersperg: Valvasor, ib., zv. IV/1, 51; Georg von Auersperg: Valvasor, ib., zv. IV/2, 446 in 449; Johannes von Auersperg: Schönleben, 1. c., 19; Valvasor, ib., zv. III, 28 in dalje. Kranjskemu kontigentu, ki je branil leta 1529 Dunaj, je pripadal tudi Trajanus von Auersperg, daljnji sorodnik Wolfganga Engelberta (Valvasor, ib., zV. IV/2, 427). - Razen teh podatkov iz literature se ni dalo izvedeti pri Avstrijskem državnem arhivu ničesar več o življenju Wolfganga Engelberta I. 
Rex Asiae et Ponti je torej po vsej verjetnosti tista poklonitvena kompozicija, ki jo je Rore priložil svojemu pismu 1. maja 1556. Glede na pričevanje tega pisma pa skladba Rex Asiae et Ponti ni edino in prvo delo, ki ga je mojster poslal Wolfgangu Engelbertu von Auerspergu, osebi, ki smo jo spoznali po Roreju kot glasbenega mecena. Katere druge kompozicije ima Rore $\mathrm{v}$ mislih, ko pravi, da je naslovljencu svojega pisma že poprej izkazoval čast, pa je doslej še neznano. Podobnost besedila kakor tudi uglasbitev bi dala misliti na latinski madrigal Musica dulci sono, ki ga tudi posreduje RISM $1565^{18}$ kot eno teh kompozicij. Zavite $\mathrm{v}$ temo pa so natančnejše okoliščine glede kraja in časa, ko se je Rore prvič približal Wolfgangu Engelbertu. Ne glede na to je kompozicija Rex Asiae et Ponti nadaljnji dokaz za zgodnjo razširjanje beneške glasbe na ozemlje današnje Slovenije, ${ }^{21}$ razširjanje, ki tedaj in še posebej v primeru Wolfganga Engelberta I. še ni bilo v zvezi s protireformacijskimi ukrepi. ${ }^{22}$ Skupno $\mathrm{z}$ mnogimi drugimi deli C. de Roreja izpričuje tudi obravnavana kompozicija vnemo mojstra - neki sodobnik ga opisuje kot človeka, »ki je neprestano težil za slavo« -, da išče in navezuje stike $\mathrm{z}$ velikaši svojega časa.

\section{SUMMARY}

The author of the paper succeeded, on the basis of the concept of the letter which was addressed by Cyprian de Rore on the 1st May 1556 in Ferrara to Wolffgano Aurspergio from Carnia, in discovering the addressee of Rore's composition »Rex Asiae et Ponti«. He found out that the Wolffgano Aurspergio of the letter and Wolffang Aurspurg, whose praises are sung in the text of the composition, were one and the same person. Thus the author concluded that Rore could have presented his composition »Rex Asiae et Ponti« to none other than Wolfgang Engelbert I of the aristocratic family Auersperg in Carniola. According to Rore's letter »Rex Asiae et Ponti« is not the only or the first composition presented by the composer to Wolfgang Engelbert I. The work dealt with in the article is also an interesting indication of an early spreading of Venetian music to the areas included in present-day Slovenia.

${ }^{21}$ Druge dokaze za to omenja že Cvetko D., La musique slovène du XVIe au XVIIe siècle v Musica antiqua Europae Orientalis, Warszawa 1966, 170.

${ }_{22}$ Sin Wolfganga Engelberta I., Hans von Auersperg, je imel na gradu Šumberk kranjskega učenjaka Samuela Budino za vzgojitelja in protestantskega pridigarja (Radics, ib., 54 in dalje). - Glede vpliva protireformacije na glasbeni repertoar ozemlja današnje Slovenije (preorientacija od Nemčije k Italiji) gl. Cvetko, 1. c., str. 170 . 